\title{
Uma proposta de ensino por meio da modelagem matemática: cálculo do volume e da área superficial de um reservatório de água
}

A proposal for teaching through the mathematical modeling: calculation of volume and surface area of a water tank

\author{
Karine Faverzani Magnago ${ }^{1}$ e Luciano de Oliveira ${ }^{2}$ \\ ${ }^{1}$ Professora Adjunta do Departamento de Matemática, Departamento de Matemática, \\ Universidade de Santa Maria, Santa Maria, Brasil \\ karine@ufsm.br \\ ${ }^{2}$ Mestre, Departamento de Matemática, \\ Universidade de Santa Maria, Santa Maria, Brasil \\ onaicul30@yahoo.com.br
}

\section{Resumo}

Nesse artigo é apresentada uma proposta de modelagem matemática para o cálculo do volume e da área superficial de um reservatório de água Nossa fundamentação teórica embasa-se no trabalho desenvolvido por Bassanezi, no sentido de ensino-aprendizagem da matemática. No final, são discutidos alguns aspectos relevantes da aplicabilidade dessa proposta em sala de aula.

Palavras-chave: Modelagem Matemática. Ensino de Matemática. Volume. Área. Reservatório de Água

\begin{abstract}
In this paper a proposal to mathematical modeling to calculate the volume and surface area of a water tank is presented. Our theoretical foundation underlies on the work of Bassanezi, in the sense teaching and learning of mathematics. In the end, we discuss some relevant aspects of the applicability of this proposal in the classroom.
\end{abstract}

Keywords: Mathematical Modeling. Mathematics Teaching. Volume. Area. Water Tank 


\section{Introdução}

O professor de matemática, no sentido de ensino e aprendizagem, enfrenta o desafio comum de justificar a necessidade e importância de se aprender esse conteúdo e mostrar sua utilidade, com o intuito de despertar o interesse dos estudantes. A dificuldade em superar esse desafio fica evidente no discurso de D'Ambrósio (1991, p. 1): “O conteúdo [matemático] que tentamos passar adiante através dos sistemas escolares é obsoleto, desinteressante e inútil".

Atualmente, com a dinâmica acelerada de acesso às informações por meio de dispositivos eletrônicos e dos avanços tecnológicos na área de comunicação, a falta de conexão entre o conteúdo trabalhado em sala de aula e a realidade dos estudantes, só agrava o desinteresse dos mesmos pelo estudo de matemática.

No sentido de oportunizar essa conexão, entra em foco o problema do cálculo do volume e da área superficial de um reservatório de água.

Conhecer o volume e a área superficial de um sólido e compreender seus significados fazem parte das mais variadas atividades do ser humano. Tomadas de decisão são realizadas com base nessas medidas, desde simples atividades cotidianas como decidir no supermercado qual apresentação de determinado produto se mostra mais vantajeosa, até a elaboração de pareceres técnicos como a determinação da capacidade de um navio. Quantos metros quadrados de azulejo são necessários na reforma de um banheiro ou quantos litros de tinta se precisa para cobrir a fachada de um edifício, são outros exemplos de decisões baseadas nesses conceitos.

Espera-se que os conceitos de volume e de área, abordados no Ensino Médio, passem a compor um rol de conhecimentos que os indivíduos disponham e usem de acordo com suas necessidades. Para esse fim, é interessante a aproximação entre esses conceitos e questões reais que determinem seu uso. A Modelagem Matemática se apresenta como uma alternativa metodológica para realizar essa aproximação pois, por meio dela, parte-se de um problema da realidade e constrói-se o desenvolvimento matemático associado adequado, de modo a auxiliar na resolução do problema. Essa afirmação concorda com a fala de Bassanezi (2011, p. 17): "A modelagem matemática, em seus vários aspectos, é um processo que alia teoria e prática, motiva seu usuário na procura do entendimento da realidade que o cerca e na busca de meios para agir sobre ela e transformála".

Por outro lado, Barbosa (2001, p.6) diz que modelagem "é um ambiente de aprendizagem no qual os alunos são convidados a problematizar e investigar, por meio da matemática, situações com referência a realidade", deslocando a posição do estudante de expectador para ator no seu processo formativo. Essa mudança de papeis, desde que trabalhada adequadamente, pode acarretar maior interesse e aprendizagem de qualidade; segundo Piazzi (2008, p. 63): "Se eu escuto... esqueço! Se eu vejo... entendo! Se eu faço... aprendo!".

Nem sempre o professor de Matemática dispõe da formação teórica e da experiência necessárias para a utilização da modelagem como metodologia de ensino. Por isso, propostas de sequências de atividades de modelagem matemática como a apresentada nesse artigo são benvindas no sentido de nortear e inspirar futuras práticas profissionais.

Nesse trabalho, será apresentada uma proposta de modelagem matemática para o cálculo do volume e da área superficial do reservatório de água presente no pátio da Estação de Tratamento de Águas (ETA), na cidade de Candelária. Essa proposta tem sua fundamentação teórica nos estudos desenvolvidos por Bassanezi $(2011$; 2012) no sentido da utilização da modelagem matemática como estratégia de ensino-aprendizagem. Ela faz parte de um conjunto de oito práticas de modelagem propostas por Oliveira (2013) em sua dissertação de mestrado. $\mathrm{O}$ tema norteador para o desenvolvimento de tais modelagens foi "tratamento e distribuição de água". O fato do autor dessa dissertação ser empregado em uma empresa, como agente de tratamento de água, contribuiu significativamente para a escolha. 
Esse artigo consta da introdução, seguida de uma breve revisão de literatura na seção 2 sobre a modelagem matemática no ensino, a luz do discurso de Bassanezi (2011; 2012), da apresentação da sequência de atividades de modelagem matemática proposta (seção 3) e, na seção 4, de discussões finais. No seguimento, encontram-se agradecimentos e referências.

\section{Modelagem Matemática no Ensino}

Uma das alternativas que os seres humanos encontraram para a interpretação do mundo e resolução de situações-problemas é a confecção de modelos que irão representar a realidade. Segundo Bassanezi (2011), modelo, nesse contexto, é um sistema artificial formalizado a partir da seleção de elementos essenciais do sistema real.

Ainda sobre modelos, Bassanezi (2011, p. 20) chama de Modelo Matemático "um conjunto de símbolos e relações matemáticas que representam de alguma forma um objeto estudado". Esse modelo se torna importante à medida que é capaz de expressar ideias sem ambiguidades, de maneira clara e simplificada.

Com relação aos aspectos matemáticos de cada modelo, Bassanezi (2011) propõe as seguintes classificações:

- Modelo linear ou não-linear: dependendo da característica da equação básica do modelo;

- Modelo estático ou dinâmico: o primeiro representa formas de objetos e o segundo simula variações de estágios do fenômeno;

- Modelo educacional ou aplicativo: o primeiro apresentando um número pequeno de suposições, quase sempre com soluções analíticas e geralmente não representa a realidade com um grau significativo de fidelidade; o segundo baseado em hipóteses realísticas e com um grande número de variáveis;

- Modelo estocástico ou determinístico, sendo que estocástico faz uso de probabilidades na descrição de um sistema e o determinístico baseado na suposição que se existem dados suficientes, então o modelo fará a previsão de maneira precisa.
Em relação a essas classificações, os dois modelos apresentados nesse trabalho são classificados como modelos não-lineares, estáticos, educacionais e determinísticos.

A partir dos esclarecimentos de modelo matemático, pode-se partir para a conceituação da modelagem matemática: "Modelagem Matemática é um processo dinâmico utilizado para a obtenção e validação de modelos matemáticos. É uma forma de abstração e generalização com a finalidade de previsão e tendências. A modelagem consiste, essencialmente, na arte de transformar situações da realidade em problemas matemáticos cujas soluções devem ser interpretadas na linguagem usual" (BASSANEZI, 2011, p. 24).

Bassanezi (2011) apresenta duas concepções para o uso da modelagem matemática: como método científico e como estratégia de ensinoaprendizagem. Sobre a segunda, associada ao conceito de modelagem adotado por ele, é possível que se obtenha melhores resultados no ensino-aprendizagem da matemática em todos os níveis, pois há uma relevante mudança de postura para alunos e professores quando se trabalha com a realidade, sendo possível o desenvolvimento de maior interesse e compreensão da matemática para os discentes, bem como um estímulo para docentes em suas práticas nos ambientes de ensino.

Bassanezi (2011) estabelece as seguintes etapas no processo de modelagem matemática:

1) Experimentação: envolve a obtenção dos dados;

2) Abstração: abrange procedimentos relacionados à formulação de Modelos Matemáticos, estabelecendo seleção de variáveis, problematização, hipóteses, simplificação;

3) Resolução: compreende o estudo analítico e numérico;

4) Validação: é a aceitação ou não do modelo. São testados resultados dos modelos e hipóteses, comparando com soluções e previsões com valores reais;

5) Modificação: consiste na reformulação de variáveis, hipóteses e conceitos empregados.

A apresentação dos dois modelos propostos nesse artigo será organizada de acordo com essas cinco etapas.

Na mesma ideia, mas esclarecendo um pouco melhor o "fazer modelagem", Bassanezi (2012) cita a iniciação da modelagem como sendo a 
escolha de temas. Isso se dá antes mesmo da experimentação. Essa atividade consiste de fazer levantamentos de possíveis situações, para que daí surja problemas diversos. É considerável que a escolha de tema seja feita pelos alunos, proporcionando a eles o sentimento de corresponsabilidade pelo processo. Mas é indispensável à orientação do professor nessa escolha para que o tema seja possível de desenvolvimento.

Vale ressaltar que, embora o que buscamos ao modelar uma situação-problema seja a validade do modelo proposto, nem sempre essa situação é necessária. Dependendo da motivação com a qual estamos trabalhando, como, por exemplo, a valorização da matemática e/ou justificação de algum conteúdo, a validação fica em um segundo plano, visto que nesse caso a aprendizagem está como alvo principal. Assim como a formulação do problema, por vezes, é mais tentadora que a sua solução.

Uma preocupação relevante é garantir uma formação, inicial ou continuada, que habilite nossos professores a trabalhar com modelagem matemática. Nessa direção, surge o questionamento: como aprender/ensinar modelagem? A resposta está no discurso de Bassanezi (2012, p. 7) que diz "a melhor maneira de se aprender modelagem matemática é fazendo modelagem, e de preferência juntamente com alguém que já teve alguma experiência".

\section{Proposta de Modelagem Matemática}

Nessa seção, é apresentada uma proposta de modelagem que consta do desenvolvimento, seguindo as etapas de Bassanezi (2011), de dois modelos: um para o cálculo do volume de um reservatório de água (subseção 3.1) e outro para o cálculo de sua área superficial (subseção 3.2). Devido aos conteúdos de cálculo de volume e de área serem desenvolvidos no Ensino Médio, essa proposta mostra-se adequada para esse nível de ensino.

Em um sistema de abastecimento de água, após o tratamento da mesma, tem-se a reservação, que é o armazenamento de grandes volumes de água tratada em reservatórios, para garantir "a continuação do processo de estabilização do desinfetante, compensar as flutuações ou variações do consumo, assegurar uma reserva de água para combate de incêndios, continuar o fornecimento de água nos casos de interrupção de adução, regular pressões e permitir interrupção do funcionamento da ETA, sem prejuízo da continuidade" (CORSAN, 2012, p. 20).

Os reservatórios são estruturas construídas "em diversos materiais: alvenaria, concreto, aço, fibra de vidro, madeira. $\mathrm{O}$ mais frequente no Brasil ainda é o emprego de concreto armado" (SANESUL, 2011, n.p.). Possuem diversas formas, sendo que as mais empregadas são a cilíndrica e a que combina cilindro e tronco de cone. Quanto à posição no terreno, os reservatórios podem ser enterrados, semienterrados, apoiados e elevados, esse último exemplificado na figura 1 .

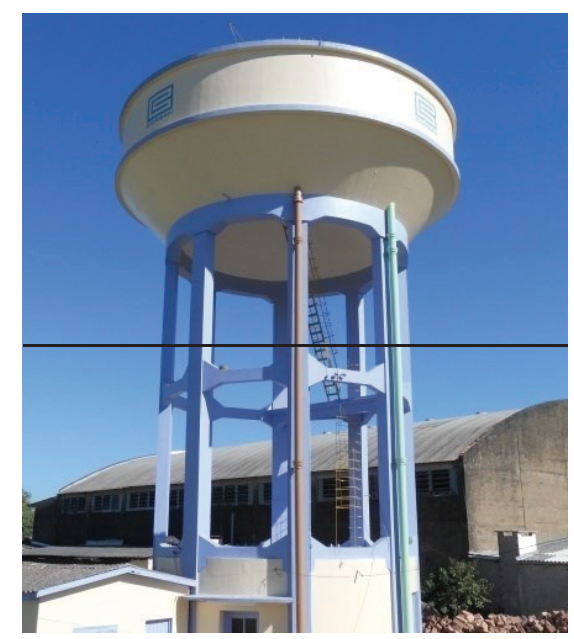

Figura 1- Reservatório elevado no pátio da ETA, em Candelária/RS.

O reservatório em destaque na figura 1 encontra-se no pátio da ETA, na cidade de Candelária; nossos modelos para determinação do volume e da área superficial são desenvolvidos referentes a esse reservatório.

O cálculo do volume é interessante por que está relacionado à capacidade do reservatório, a principal característica funcional do mesmo. Já o cálculo da área superficial pode se relacionar à quantidade de material empregado na sua construção, compondo seu custo (fator essencial para qualquer empreendimento comercial) como também à manutenção da unidade de reservação, como pinturas, por exemplo.

$\mathrm{Na}$ prática da ETA, a principal informação sobre um reservatório é a sua capacidade. Nesse caso, o valor é conhecido pelos agentes de tratamento e é de $250000 \mathrm{~L}\left(250 \mathrm{~m}^{3}\right)$. Porém, o 
desenvolvimento desse modelo, para o estudo e aplicabilidade da matemática, é muito significativo, uma vez que esse reservatório, em específico, não é formado exclusivamente por um único sólido geométrico, e sim por uma combinação de alguns deles.

\subsection{Volume do reservatório}

1) Experimentação:

Primeiramente, foram realizadas observações no reservatório no que se refere a formas e medidas necessárias para a determinação do volume.

A primeira vista, olhando por baixo, a forma do reservatório não é única; ele parece ser formado por dois sólidos - abaixo por um tronco de cone e acima por um cilindro. Além disso, no centro desses sólidos existe uma passagem para uma pessoa, que lembra um cilindro.

Em seguida, após autorização, foram realizadas medições no próprio reservatório, onde fosse possível. Foi levantada a seguinte medida:

- diâmetro da base menor do tronco de cone: $7 \mathrm{~m}$. Essa medida foi realizada no chão, usando como referência os pilares de sustentação do reservatório.

Como não foi possível fazer mais nenhuma medida, foi realizada uma consulta com um funcionário que havia feito manutenções dentro do reservatório. O mesmo relatou que:

- O teto do reservatório é como um "pedaço de uma bola"; a parte de baixo do reservatório também é assim; essa parte de baixo se une diretamente a parte inclinada; e o topo da "bola" e o final da parte inclinada parecem estar na mesma altura; o acesso ao reservatório é feito de baixo para cima, por um tipo de "poço de visita", que quase no topo tem uma portinhola, quadrada, que fica na lateral do poço de visita e tem, aproximadamente, $50 \mathrm{~cm} \times 50 \mathrm{~cm}$; para o teto, a partir dessa portinhola, tem-se em torno de $30 \mathrm{~cm}$; a parte de baixo da portinhola se encontrava alinhada com o final da parede vertical do reservatório; a altura dessa parede era da altura dele, com o braço esticado e segurando o rolo de pintura; a distância da parte inclinada, em linha reta, era da "escada de ferro", que ele estava usando; o poço de visita tinha a largura de $80 \mathrm{~cm}$.

Com isso, foram feitas as medidas:
- altura do funcionário, com braço esticado: 2,25 m; aproximação, para o mesmo segurando o rolo de pintura: $2,35 \mathrm{~m}$;

- comprimento da escada usada: 2,30 m;

- dimensões da portinhola: 0,50 $\mathrm{m} \times 0,50 \mathrm{~m}$;

- diâmetro da base do cilindro do poço de visita: $0,80 \mathrm{~m}$;

- altura da portinhola até o teto: $0,30 \mathrm{~m}$.

Mesmo com todas essas informações, ainda faltava uma medida muito importante: o diâmetro da parte cilíndrica. Consultado os demais funcionários da ETA, nenhum soube informar tal medida. Porém, foi lembrado pelos agentes de tratamento que quando se desliga a proteção de nível máximo do reservatório, esse extravasa por uma abertura próximo da parede vertical, caindo água e deixando uma marca no chão. A partir dessa marca, mostrada pelo agente, foi feita uma linha reta até o pilar, na parte interior (onde foi feita a medida do diâmetro da base menor do tronco do cone). Daí:

- medida da posição em que a água cai e o pilar: $1,80 \mathrm{~m}$.

A partir disso, foi possível entender quais sólidos geométricos deveriam ser empregados para a determinação do volume: cilindro, tronco do cone, calota da esfera (que é a parte do "pedaço da bola", que foi citado). Então, optouse por construir uma maquete, de forma compartimentada (figura 2 e 3), para melhor visualização de todo o sólido.

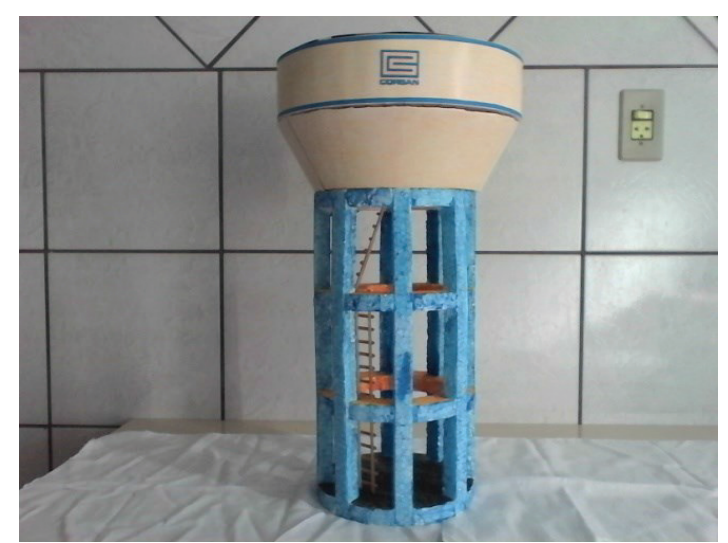

Figura 2- Maquete do reservatório elevado do pátio da ETA. 


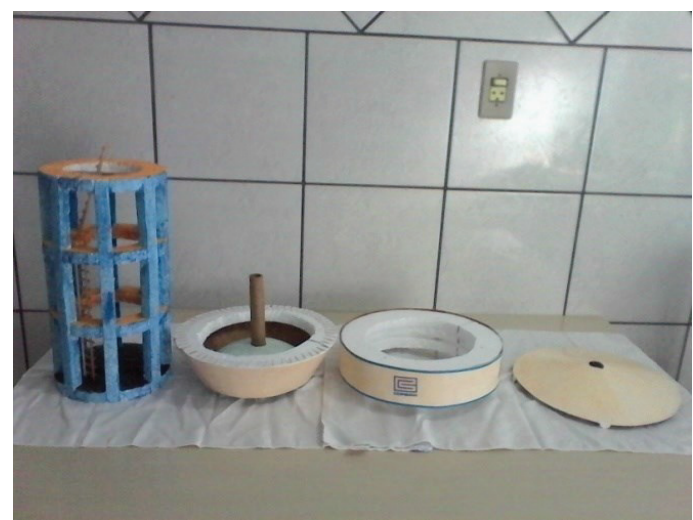

Figura 3- Maquete do reservatório elevado do pátio da ETA visto de forma compartimentada.

Daí se buscou as expressões que representavam o volume desses sólidos. São elas:

- Volume do cilindro:

$$
V=\pi \cdot r^{2} \cdot h,
$$

sendo $r$ o raio da base e $h$ a altura;

- Volume do tronco do cone:

$$
V=\frac{\pi \cdot h}{3} \cdot\left(R^{2}+R \cdot r+r^{2}\right),
$$

sendo $R$ o raio da base maior, $r$ o raio da base menor e $h$ a altura;

- Volume da calota da esfera:

$$
V=\frac{\pi \cdot h}{6} \cdot\left(3 \cdot a^{2}+h^{2}\right)
$$

sendo $a$ o raio do círculo da calota e $h$ a altura.

Para melhor entendimento, chamar-se-á de "calota inferior" a base do reservatório e de "calota superior" o teto. Também, usar-se-á "cilindro do reservatório" para a parte do reservatório de forma cilíndrica, além de "tronco do cone" para a parte nesse formato e "poço de visita" para a parte cilíndrica no centro do reservatório, para a entrada na parte interna do mesmo, conforme figuras 4, 5, 6, 7 e 8.

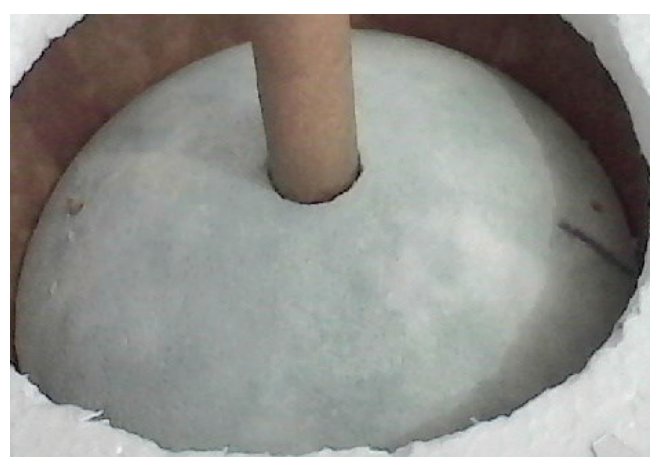

Figura 4- Parte da Maquete do reservatório: calota inferior.

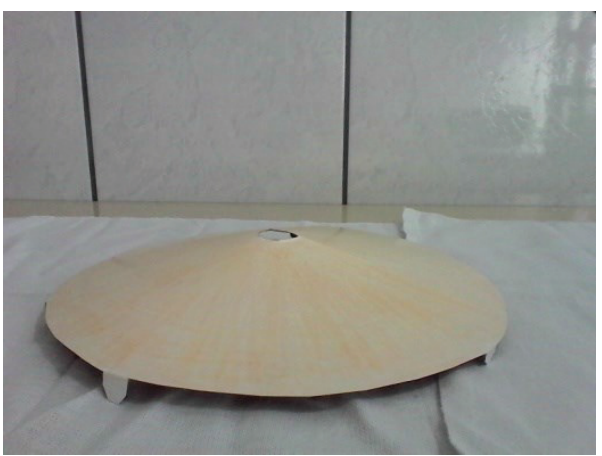

Figura 5- Parte da Maquete do reservatório: calota superior.

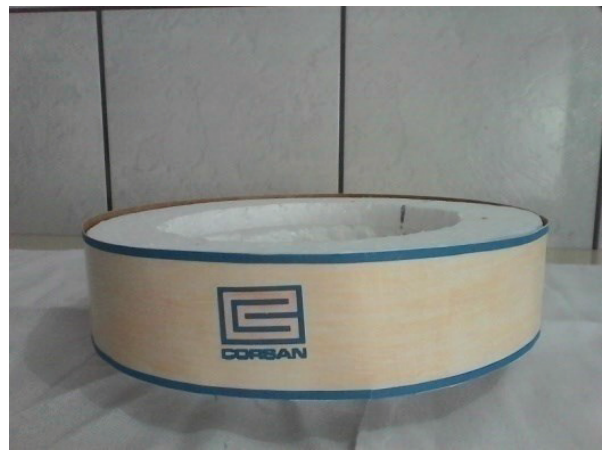

Figura 6- Parte da Maquete do reservatório: cilindro do reservatório.

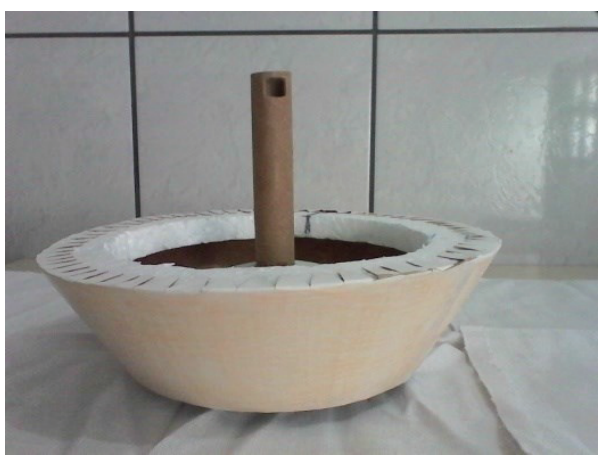

Figura 7- Parte da Maquete do reservatório: tronco do cone.

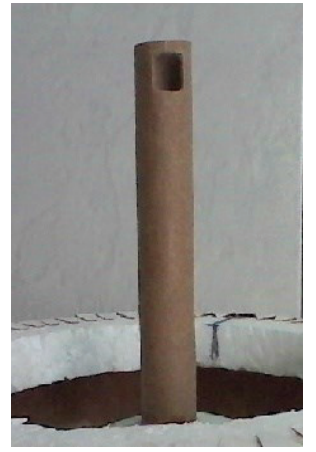

Figura 8- Parte da Maquete do reservatório: poço de visita. 


\section{2) Abstração:}

Na formulação desse modelo, serão usadas as variáveis, sendo os volumes expressos $\mathrm{em}^{3}$ e as medidas de comprimento em $\mathrm{m}$ :

- $V_{T}$ : volume total do reservatório;

- $V$ : volume do cilindro do reservatório;

- $V_{p}$ : volume do poço de visita;

- $V_{t c}$ : volume do tronco do cone;

- $V_{e}$ : volume da calota inferior;

- $h_{1}$ : altura do cilindro do reservatório;

- h2: altura do tronco de cone e da calota inferior;

- r1: raio da base do cilindro do reservatório, que é o mesmo raio da base maior do tronco do cone;

- $r_{2}$ : raio da base menor do tronco do cone;

- r3: raio da base do poço de visita.

Consideraram-se como hipóteses, nesse modelo, que as medidas realizadas são todas na parte interna das figuras, desconsiderando a medidas das paredes do reservatório e que todas as afirmações coletadas pelas entrevistas estão corretas.

\section{3) Resolução:}

Para a resolução, é importante que os dados coletados sejam adequados para a sua utilização na equação a ser proposta no modelo, como segue:

- o raio da base menor do tronco do cone é a metade do seu diâmetro:

$$
r_{2}=\frac{7}{2}=3,50 \mathrm{~m}
$$

- o raio do cilindro do reservatório é a soma do raio da base menor do tronco do cone com a medida onde a água cai:

$$
r_{1}=3,50+1,80=5,30 \mathrm{~m} \text {; }
$$

- o raio do poço de visita é a metade do seu diâmetro:

$$
r_{3}=\frac{0,80}{2}=0,40 \mathrm{~m}
$$

- a altura do cilindro do reservatório e do poço de visita, para o volume, é a mesma:

$$
h_{1}=2,35 \mathrm{~m} \text {. }
$$

A altura do tronco do cone e da calota inferior não pode ser obtida diretamente. Porém, representando a parte do tronco do reservatório por um corte (figura 9), é possível determinar a altura, usando o teorema de Pitágoras no triângulo ABC.

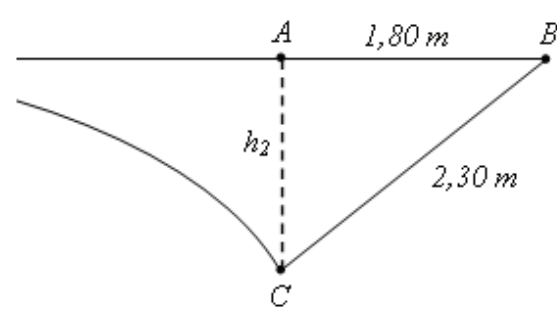

Figura 9- Desenho em corte do tronco de cone do reservatório.

Aplicando o teorema, tem-se:

$$
\begin{gathered}
\overline{B C}^{2}=\overline{A B}^{2}+\overline{A C}^{2} \\
2,3^{2}=1,8^{2}+h_{2}{ }^{2} \\
h_{2}=\sqrt{2,05} \\
h_{2}=1,431782 \ldots \cong 1,43 \mathrm{~m} .
\end{gathered}
$$

A partir da análise das partes do reservatório, foi possível de se verificar que:

- para o volume total, deve ser adicionado o volume do cilindro do reservatório com a parte que parece o tronco de cone e descontado o volume do poço de visita;

- o volume da parte que se observa como o tronco do cone é a diferença entre o volume da calota inferior e o volume do tronco do cone;

- no cálculo do volume total, a calota superior não é considerada, pois não é ocupada com água.

Com isso, tem-se:

$$
\begin{gathered}
V_{T}=V_{c}+\left(V_{t c}-V_{\theta}\right)-V_{p} \\
V_{T}=V_{c}+V_{t c}-V_{\theta}-V_{p} .
\end{gathered}
$$

Usando a equação (1), pode-se escrever o volume do cilindro do reservatório $\left(V_{c}\right)$ e o volume do poço de visita $\left(V_{p}\right)$ :

$$
\begin{aligned}
& V_{c}=\pi \cdot r_{1}{ }^{2} \cdot h_{1^{\prime}} \\
& V_{p}=\pi \cdot r_{3}{ }^{2} \cdot h_{1} .
\end{aligned}
$$

Com a equação (2), tem-se o volume do tronco do cone $\left(V_{t c}\right)$ :

$$
V_{t c}=\frac{\pi \cdot h_{2}}{3} \cdot\left(r_{1}^{2}+r_{1} \cdot r_{2}+r_{2}^{2}\right)
$$

E com a expressão (3), tem-se o volume da calota inferior $\left(V_{e}\right)$ :

$$
V_{\theta}=\frac{\pi \cdot h_{2}}{6} \cdot\left(3 \cdot r_{2}{ }^{2}+h_{2}{ }^{2}\right) \text {. }
$$

Substituindo (14), (15), (16) e (17) em (13), tem-se:

$$
\begin{aligned}
V_{T} & =\pi \cdot r_{1}{ }^{2} \cdot h_{1} \\
& +\frac{\pi \cdot h_{2}}{3} \cdot\left(r_{1}{ }^{2}+r_{1} \cdot r_{2}+r_{2}{ }^{2}\right) \\
& -\frac{\pi \cdot h_{2}}{6} \cdot\left(3 \cdot r_{2}{ }^{2}+{h_{2}}^{2}\right)-\pi \cdot r_{3}{ }^{2} \cdot h_{1} .
\end{aligned}
$$


Propositalmente, não será feita a simplificação da expressão (18) para que seja possível visualizar cada um dos volumes. Substituindo as incógnitas pelos valores encontrados e adotando $\pi=3,14$, tem-se:

$$
\begin{gathered}
V_{T} \cong 207,2761+88,1426 \\
-29,0328-1,1806 \\
V_{T} \cong 265,2053 \mathrm{~m}^{3} .
\end{gathered}
$$

\section{4) Validação e modificação:}

Embora se observe um erro considerável de $15 \mathrm{~m}^{3}$ entre o valor do volume encontrado e o valor usado na ETA, a saber, $250 \mathrm{~m}^{3}$, se deve levar em consideração que os valores utilizados, na sua grande maioria, não foram medições físicas, realizadas no interior do reservatório, o que já gera um erro. Cita-se, principalmente, a aproximação do raio do cilindro do reservatório que foi determinado por uma marca da queda de água do reservatório. Além disso, não havia na ETA nenhuma planta que pudesse ratificar o valor de $250 \mathrm{~m}^{3}$ usado como referência de volume.

Ainda assim, o modelo encontrado pode ser considerado bom do ponto de vista educacional, uma vez que na sua construção não havia uma preocupação em se encontrar o resultado exato e sim em realizar um desenvolvimento adequado para o cálculo do volume.

\section{2 Área superficial do reservatório}

\section{1) Experimentação:}

Aqui, utilizaram-se os dados e informações obtidos no modelo do volume, com algumas adequações para o cálculo da área.

Os sólidos geométricos que dever ser empregados para a determinação da área, novamente são: o cilindro, tronco do cone, calota da esfera. Para essas figuras geométricas e para o cálculo da área do reservatório as expressões que representam as áreas necessárias são:

- área lateral do cilindro:

$$
A L=2 . \pi \cdot r \cdot h \text {, }
$$

sendo $r$ o raio da base e $h$ a altura;

- área lateral do tronco do cone:

$$
A L=\pi \cdot g \cdot(R+r),
$$

sendo $R$ o raio da base maior, $r$ o raio da base menor e $g$ a geratriz;
- área da calota da esfera:

$$
A=\pi \cdot\left(h^{2}+a^{2}\right),
$$

sendo $a$ o raio do círculo da calota e $h$ a altura.

2) Abstração:

Na formulação desse modelo, serão usadas as variáveis, sendo as áreas expressas em $\mathrm{m}^{2} \mathrm{e}$ as medidas de comprimento em $\mathrm{m}$ :

- Ат: área total do reservatório;

- ALc: área lateral do cilindro do reservatório;

- ALp: área lateral do poço de visita;

- ALtc: área lateral do tronco do cone;

- Aei: área da calota inferior;

- Aes: área da calota superior;

- g: geratriz do tronco do cone;

- h3: altura da calota superior;

- h4: altura do poço de visita, até o teto; além das medidas de comprimento já apresentadas no modelo do volume: $h_{1}, h_{2}, r_{1}$, $r_{2}, r_{3}$.

Para esse modelo, devem ser consideradas as hipóteses já empregadas no modelo do volume, além de se considerar desprezível a área da portinhola.

3) Resolução:

Além dos valores de $r_{1}, r_{2}, r_{3}, h_{1}, h_{2}$, já nominados ou calculados no modelo do volume, ainda são necessárias:

- a geratriz $g$ do tronco do cone, que é a altura da escada de ferro:

$$
g=2,30 \mathrm{~m} \text {; }
$$

- a altura da calota superior, que é a soma da medida da altura da portinhola mais 0,30 m, conforme citado na entrevista. Então:

$$
h_{3}=0,50+0,30=0,80 \mathrm{~m} \text {; }
$$

- a altura do poço de visita, até o teto, que é a soma da altura do cilindro do reservatório com a altura da calota superior:

$$
h_{4}=2,35+0,80=3,15 \mathrm{~m} \text {. }
$$

Sabendo esses valores e com a análise da maquete, foi possível verificar que para o cálculo da área total é necessária a seguinte expressão:

$$
\begin{aligned}
A_{T}= & A L_{c}+A L_{p}+A L_{t c} \\
& +A_{\theta i}+A_{\theta s} .
\end{aligned}
$$

Usando as equações (21), (22) e (23), podemos escrever as respectivas áreas da equação (27) de acordo com as variáveis, como segue: 


$$
\begin{gathered}
A L_{c}=2 \cdot \pi \cdot r_{1} \cdot h_{1}, \\
A L_{p}=2 \cdot \pi \cdot r_{3} \cdot h_{4}{ }^{\prime} \\
A L_{t c}=\pi \cdot g \cdot\left(r_{1}+r_{2}\right), \\
A_{\theta i}=\pi \cdot\left(h_{2}{ }^{2}+r_{2}{ }^{2}\right), \\
A_{s s}=\pi \cdot\left({h_{3}}^{2}+{r_{1}}^{2}\right) .
\end{gathered}
$$

Substituindo as equações (28) à (32), na equação (27), tem-se a expressão para o cálculo da área do reservatório:

$$
\begin{gathered}
A_{T}=2 \cdot \pi \cdot r_{1} \cdot h_{1}+2 \cdot \pi \cdot r_{3} \cdot h_{4} \\
+\pi \cdot g \cdot\left(r_{1}+r_{2}\right)+\pi \cdot\left(h_{2}{ }^{2}+r_{2}{ }^{2}\right) \\
+\pi \cdot\left(h_{3}{ }^{2}+r_{1}{ }^{2}\right) \cdot
\end{gathered}
$$

Substituindo as incógnitas pelos valores encontrados e adotando $\pi=3,14$, tem-se:

$$
\begin{gathered}
A_{T} \cong 78,2174+7,9128+63,5536 \\
+47,4332+90,2122 \\
A_{T} \cong 287,3292 \mathrm{~m}^{2}
\end{gathered}
$$

4) Validação e modificação:

Nesse modelo não foi possível confirmar o valor encontrado, pois não existe esse dado na ETA. Novamente aqui não há uma preocupação muito grande com a validade do resultado, mas sim com o desenvolvimento do modelo.

\subsection{Conceitos Relacionados}

Os dois modelos se baseiam nas figuras geométricas sólidas (cilindros, tronco de cone e calotas de esfera), e suas expressões para cálculo de volumes e áreas, juntamente com as unidades de medidas de comprimento (com transformações de submúltiplos), de área e de volume. Nesses modelos, cálculos envolvendo as quatro operações, potências e raízes quadradas de números decimais são empregados, demonstrando o quanto esse conhecimento é indispensável.

A capacidade de visualização e interpretação geométrica também esteve presente no desenvolvimento do modelo, assim como a transcrição de dados em incógnitas.

\section{Discussões Finais}

Sugere-se que essa sequência de atividades de modelagem inspire professores de matemática para a utilização dessa metodologia em suas salas de aula. Ela pode ser seguida nos moldes do que foi exposto ou adaptada à realidade da escola na qual será aplicada.

É interessante que os estudantes realizem uma visita de pesquisa ao local do reservatório. Organizados em pequenos grupos, eles poderiam tecer suas hipóteses sobre os sólidos que compõe o reservatório, realizar as próprias medições e as entrevistas com os funcionários locais que julgarem apropriadas.

Em particular, se o reservatório for em uma estação de tratamento, como o usado nesse desenvolvimento, a visita pode ser tornar mais interessante e de caráter interdisciplinar pois várias outras questões poderiam ser abordadas nesse ambiente, como, por exemplo, o uso responsável da água (associada à disciplina de biologia), processos físico-químicos de tratamento da água (associada às disciplinas de química e física), pressão de distribuição de água (associada a disciplina de física), capitação de água para abastecimento (associada à disciplina de geografia), etc.

Ainda, a visita poderia ser realizada após a apresentação dos conceitos de área e volume, como demonstração de aplicabilidade desses conteúdos e reforço dos conceitos, ou antes da apresentação formal dos mesmos. Nesse segundo caso, a visita serviria de estímulo para a apresentação desses conceitos matemáticos que seriam desenvolvidos e formalizados em conjunto com a prática.

Com relação à aprendizagem, destacam-se algumas características singulares do desenvolvimento dessa proposta em sala de aula, raramente presentes na disciplina de matemática.

Primeiramente, a sequência de atividades estimula a visualização "geometrizada" da realidade, propiciando uma conexão entre o concreto e o abstrato; em particular, a construção da maquete pode contribuir muito nesse aspecto, caso fosse realizada.

Também seriam estimuladas, nos estudantes, a capacidade de observação e síntese de dados, bem como sua criatividade. Eles teriam de ser criativos para realizarem medições e proporem hipóteses.

Ainda, seriam desenvolvidas habilidades de trabalho em grupo e de expressão oral e escrita, sem que se deixasse de exigir o rigor matemático esperado para tal nível de ensino. 


\section{Agradecimentos}

Os autores agradecem ao Mestrado Profissional em Matemática em Rede Nacional (PROFMAT - Santa Maria) pela oportunidade de desenvolver esse trabalho.

\section{Referências}

BARBOSA, J. C. (2001). Modelagem na educação matemática: contribuições para o debate teórico. In: REUNIÃO ANUAL DA ANPED, 24.,2001, Caxambu.

BASSANEZI. (2011) Ensino-aprendizagem com modelagem matemática: Uma nova estratégia, 3. ed., Contexto.

BASSANEZI, R. C. (2012). Temas \& modelos, 1. ed., UFABC.

CORSAN. (2012) Superintendência de tratamento. Curso básico de tratamento de água - I: Reservação. Porto Alegre.

D’AMBRÓSIO, U. (1991). Matemática, ensino e educação: uma proposta global. Temas \& Debates, Rio Claro, ano IV, n. 3, p.1-15.

OLIVEIRA, L. (2013). Modelagem Matemática no Tratamento e na Distribuição de Água: Propostas para o ensino de matemática. Dissertação (Mestrado em Matemática). Mestrado Profissional em Matemática em Rede Nacional, Santa Maria.

PIAZZI, P. (2008). Aprendendo inteligência: manual de instruções do cérebro para alunos em geral, 2.ed.rev., Aleph.

SANESUL. (2011). Abastecimento de água: A distribuição da água. In: SANESUL. Abastecimento de água. Disponível em: $<$ www.sanesul.ms.gov.br/conteudos.aspx?id= 5>. Acesso em: 19 abr. 2013. 